\title{
Cloning and disruption of the ornithine decarboxylase gene of Ustilago maydis: evidence for a role of polyamines in its dimorphic transition
}

\author{
Lorenzo Guevara-Olvera, ${ }^{1,3}$ Beatriz Xoconostle-Cázares ${ }^{1}$ \\ and José Ruiz-Herrera', ${ }^{1,2}$
}

Author for correspondence: José Ruiz-Herrera (Departamento de Ingeniería Genética). Tel: +5246239600 . Fax: +52 462 45849. e-mail: jruiz@irapuato.ira.cinvestav.mx

1,2 Departamentos de Ingeniería Genética (Unidad Irapuato) ${ }^{1}$ and Genética y Biología Molecular (Unidad México, DF) ${ }^{2}$, Centro de Investigación y de Estudios Avanzados del IPN, Apartado Postal 629, Irapuato, Gto, 36500 . Mexico

3 Instituto Tecnológico de Celaya, México

\begin{abstract}
The gene encoding ornithine decarboxylase (ODC) from Ustilago maydis was cloned. A conserved PCR product amplified from $U$. maydis DNA was synthesized and used to screen a genomic library of the fungus. Alignment of its deduced protein sequence with those of other cloned ODCs showed a high degree of homology. Gene replacement was obtained by removal of a central part of the gene and insertion of the hygromycin resistance cassette. The null mutant thus obtained displayed no ODC activity and behaved as a polyamine auxotroph. This result is evidence that a single ODC gene exists in the fungus, and that $U$. maydis utilizes the ODC pathway as the only mechanism for polyamine biosynthesis. When grown in polyamine-containing media, the null mutant accumulated a polyamine pool which further sustained its normal rate of growth in polyamine-free media for approximately 12-16 $\mathrm{h}$. When putrescine concentrations lower than $0.5 \mathrm{mM}$ were employed, the mutant grew at a normal rate but was unable to engage in the dimorphic transition. Under conditions favourable for mycelial growth, the mutant grew with a yeast-like morphology in liquid media, and formed smooth colonies consisting of yeast cells on solid media. Reversion to normal dimorphic phenotype required high concentrations of putrescine or spermidine. These results are evidence that concentrations of polyamines higher than those necessary to sustain vegetative growth are required for the dimorphic transition in $U$. maydis.
\end{abstract}

Keywords: Ustilago maydis dimorphism, ornithine decarboxylase gene, ornithine decarboxylase mutants, polyamine synthesis

\section{INTRODUCTION}

Polyamines are basic cationic micromolecules essential for the growth of all organisms (Pegg \& McCann, 1982; Tabor \& Tabor, 1984, 1985). Because of their positive net charge, it has been considered that polyamines exert their multiple functions by binding to negatively charged molecules of the cell, mainly nucleic acids. Among the many roles played by polyamines, it has been described

Abbreviations: DAB, 1,4-diamino-2-butanone; ODC, ornithine decarboxylase.

The GenBank accession number for the sequence reported in this paper is X88796. that they protect DNA from enzymic degradation, Xray irradiation, mechanical shearing and oxidative damage. They also stabilize RNA, prevent ribosome dissociation, and in vitro they stimulate DNA and RNA synthesis and improve the fidelity of translation (McCann et al., 1987). A role for polyamines in cell differentiation has also been substantiated (Pegg \& McCann, 1982; Tabor \& Tabor, 1984, 1985; RuizHerrera, 1994; Slocum et al., 1984), although no clearcut mechanisms for this role have been demonstrated. In general, it has been considered that this specific function is only an extension of their general effects on growth. In animals and fungi, the first enzyme specifically involved in polyamine biosynthesis is ornithine decarboxylase (ODC), responsible for the synthesis of putrescine 
(Davis et al., 1992; Tabor \& Tabor, 1984, 1985). Mutants affected in the catalytic polypeptide of ODC are polyamine auxotrophs (Davis et al., 1987; Balasundaram et al., 1994).

We have described in several fungal models that the levels of ODC and polyamine pools increase previous to all differentiative steps: spore germination (CalvoMendez et al., 1987), sporulation (Martinez-Pacheco et al., 1989; Reyna-Lopez \& Ruiz-Herrera, 1993) and dimorphic transition (Martinez-Pacheco et al., 1989; Guevara-Olvera et al., 1993). If this increase in the polyamine pools is blocked by addition of the ODC competitive inhibitor 1,4-diamino-2-butanone (DAB), differentiation is prevented, without serious alterations in cell growth (Ruiz-Herrera \& Calvo-Mendez, 1987; Martinez-Pacheco et al., 1989; Reyna-Lopez \& RuizHerrera, 1993; Guevara-Olvera et al., 1993). Specificity of the effect of the inhibitor is supported by the observation that putrescine addition reverses the effect of DAB. More decisive evidence for the specific role of high levels of polyamines in cell differentiation would be provided by controlling their concentrations in auxotrophic mutants. In the present study, we have isolated an odc null mutant of Ustilago maydis by means of reverse genetics. U. maydis is a plant-pathogenic fungus responsible for corn smut. The fungus displays a complex life cycle with two alternating phases: a haploid stage, characterized by its saprophytic yeast-like growth; and a dikaryotic stage during which the fungus grows as a mycelium and invades the host plant (Banuett, 1992). Recently we have developed conditions which permit the dimorphic transition of haploid strains in liquid or solid media (Ruiz-Herrera et al., 1995a). An especially attractive feature of $U$. maydis is that it has a well-developed genetic system, and all the molecular tools which permit its easy manipulation by recombinant DNA techniques (Fotherinham \& Holloman, 1989, 1990; Wang et al., 1988). We have thus proceeded to the cloning of the ODC gene of the fungus, its substitution, and the analysis of the phenotype of the null mutant obtained.

\section{METHODS}

Strains and culture media. FB1 $\left(a_{1} b_{1}\right)$ and FB2 $\left(a_{2} b_{2}\right)$ strains of $U$. maydis (F. Banuett, University of California, San Francisco, USA) were used in this study. They were maintained and propagated in the yeast or mycelial forms as described previously (Ruiz-Herrera et al., 1995a). U. maydis grows with yeast-like morphology at $\mathrm{pH} \mathrm{7,} \mathrm{and} \mathrm{in} \mathrm{the} \mathrm{mycelial} \mathrm{form} \mathrm{at} \mathrm{pH}$ 3 (Ruiz-Herrera et al., 1995a). When necessary, hygromycin $\left(200 \mu \mathrm{g} \mathrm{ml}^{-1}\right)$ and/or putrescine or spermidine were added to minimal medium (Holliday, 1974). Escherichia coli strains DH $5 \propto$ mcr and KW258 were used for transformation, and for plasmid and phage propagation, respectively. They were grown in LB broth containing $10 \mathrm{mM} \mathrm{MgSO}_{4}$ and $2 \%(\mathrm{w} / \mathrm{v})$ maltose, or ETB media containing the necessary antibiotics for selection.

DNA techniques. Restriction enzymes and modifying enzymes were from BRL, except SalI, which was obtained from Boehringer. They were employed according to the instructions of the suppliers. DNA-DNA (Southern) hybridizations utilizing $\left[\alpha-{ }^{32} \mathrm{P}\right] \mathrm{dCTP}$-labelled probes were performed under high stringency according to Sambrook et al. (1989). Transformation of $U$. maydis was carried out by the method of Tsukuda et al. (1988).

DNA was sequenced by the dideoxynucleotide termination method (Sanger et al., 1977) using the Sequenase kit (version 2.0 ; USB). Single- or double-stranded DNA was used as template. The terminal sequences of the cloned fragments were obtained using the forward and reverse universal primers. Additional primers were designed to extend the sequences.

Screening of the genomic library. The genomic library of $U$. maydis RK32 $\left(a_{2} b_{3}\right)$ constructed in AEMBL3 was obtained from Regine Kahmann (Universität München, Germany). The labelled Umodc PCR product (Torres-Guzman et al., 1996) was used to screen the library. Positive phages were amplified in $E$. coli KW258. Inserts were recovered, digested with SalI, and probed by hybridization with the PCR product. The positive fragments of approximately $4-5 \mathrm{kbp}$ were subcloned in Bluescript $\mathrm{KS}(+)(\mathrm{pBKS}+)$ and propagated. Since similar restriction maps were displayed by three clones, one of them was selected for further studies.

RNA extraction and Northern hybridization. RNA was extracted using a slight modification of the lithium method (Sambrook et al., 1989). RNA was separated by electrophoresis in formaldehyde/agarose gels, transferred to Hybond- $\mathrm{N}^{+}$membranes (Amersham) and hybridized. A radiolabelled Pst $-X$ hol $0.9 \mathrm{kbp}$ fragment of the gene was used as a probe under stringent conditions (Sambrook et al., 1989). RNA concentrations were normalized by hybridization with the carboxin resistance gene (Keon et al., 1991).

Other methods. Cell morphology of $U$. maydis grown in liquid medium was scored by microscopic observation of samples stained with cotton blue. At least 200 cells were scored in each experiment. Cells and colonies were observed and photographed with a Zeiss microscope (Jena). ODC was measured in whole cells as described previously (GuevaraOlvera et al., 1993). Cell growth was measured by dry weight or protein determination as described by Ruiz-Herrera et al. (1995a). Protein was measured by the Folin method. $U$. maydis-infected corn ears were obtained by inoculation of young plants with a mixture of FB1 and FB2 U. maydis cell suspensions. Naturally infected corn ears were obtained from a local supplier.

\section{RESULTS}

\section{Inhibition of teliospore germination and yeast-to- mycelium transition by DAB}

Teliospores obtained from galls developed in artificially or naturally infected corn were incubated on solid plates of minimal medium with or without $20 \mathrm{mM}$ DAB. Germination was followed for $48 \mathrm{~h}$ and scored. At the concentration used, DAB inhibited teliospore germination by more than $97 \%$ (Table 1). A similar degree of inhibition $(88 \%)$ of the yeast-to-mycelium transition of the fungus was brought about by the same $\mathrm{DAB}$ concentration, whereas growth inhibition was only of the order of $30 \%$ (Table 1). These results suggested that, as described in other fungi (Ruiz-Herrera, 1994), poly- 
Table 1. Inhibition of teliospore germination and yeast-to-mycelium transition by DAB

\begin{tabular}{|c|c|c|c|c|c|}
\hline \multirow[t]{2}{*}{ Parameter } & \multirow{2}{*}{$\begin{array}{c}\text { DAB } \\
(\mathrm{mM})\end{array}$} & \multicolumn{2}{|c|}{ Germinating teliospores* } & \multirow[t]{2}{*}{ Growth $†$} & \multirow{2}{*}{$\begin{array}{c}\text { Mycelial } \\
\text { cells }(\%) \neq\end{array}$} \\
\hline & & $\begin{array}{l}\text { Natural } \\
\text { infection }\end{array}$ & $\begin{array}{l}\text { Artificial } \\
\text { infection }\end{array}$ & & \\
\hline \multirow[t]{2}{*}{ Teliospore germination } & 0 & 67,90 & 930,950 & NA & NA \\
\hline & 20 & 0,2 & 0,0 & NA & NA \\
\hline \multirow[t]{4}{*}{ Dimorphic transition } & 0 & NA & NA & $1 \cdot 6$ & 99 \\
\hline & 5 & NA & NA & $1 \cdot 7$ & 68 \\
\hline & 10 & $\mathrm{NA}$ & NA & $1 \cdot 2$ & 33 \\
\hline & 20 & NA & NA & $1 \cdot 1$ & 12 \\
\hline
\end{tabular}

NA, Not applicable.

* Mean number of teliospores germinated in three plates from two different experiments. Plates were inoculated with 500 or 1000 teliospores obtained from naturally or artificially infected ears, respectively.

†Dry weight $\left(\mathrm{mg} \mathrm{ml}^{-1}\right)$. Means of three experiments.

$\ddagger$ Means of three experiments.

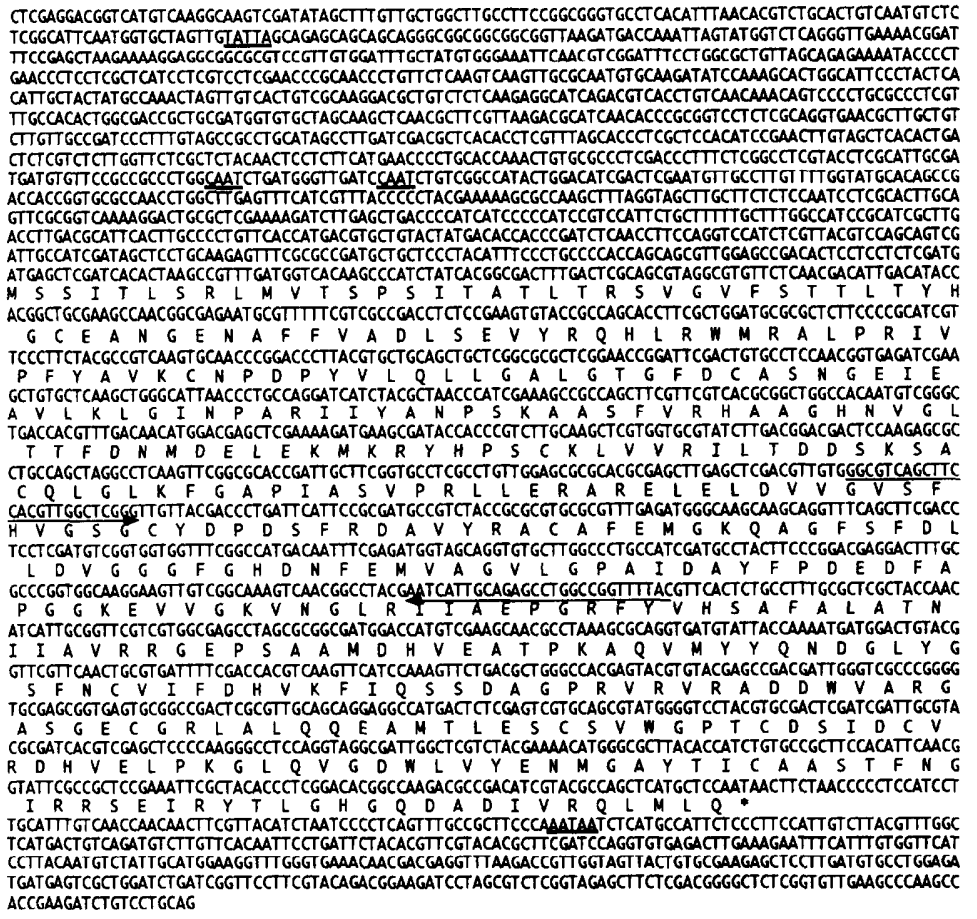

CTCGAGGACGGTCATGT CAAGGCAAGT CGATATAGCTTTGT GCTGGCTTGCCTTCCGGCGGGTGCCT CACATTTAACACGTCTGCACTGTCAATGTCTC TCGGCATTCAATGGTGCTAGTTGIATIAGCAGAGCAGCAGCAGGGCGGCGGCGGCGGTTAAGATGACCAAATTAGTATGGT CT CAGGGTT GAAAACGGAT GAACCCTCCTCGCTCATCCTCGCCTCGAACCCGCAACCCTGTTCTCAAGT CAAGTTGCGCAATGTGCAAGATATCCAAAGCACTGGCATTCCCTACTCA CATTGCTACTATGCCAAACTAGTT GCACTGT GGCAAGGACGCT GTTCT CAAGAGGCATCAGACGT CACCTGTCAACAAACAGTCCCCTGCGCCCTCG TIGCACACTGGCGACCGCTGCGATGGGTGCTAGCAAGCTCAACGCTT CGTTAAGACGCATCAACACCCGCGGTCCTCCGCAGT GAGCTCACACT ТTCG TCT GGTT CT CGCTCTACAACTCCT CTT CAT GAACCCCTGCACCAAACTGT GCGCCCT CGACCCTTTCTCGGCCTCG ACCT CGCATTGCGA TGATGTGT CCGCCGCCCT GGGAATCT GAT GGGTT GAT CCAAICT TCGGCCATACTGGACATCGACTCGAATGITGCCTT GI IT GGTATGCACAGCCG

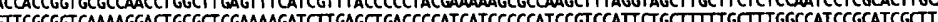
作 ATGAGCT CGATCACACTAAGCCGTI GATGGTCACAAGCCCATCTATCACGGCGACTIGACGGCAGCGTAGGCGT GTCTCAACGACATT GACATAC $\begin{array}{lllllllllllllllllllllllllllllll}S & S & I & T & L & S & R & L & M & V & T & S & P & S & I & T & A & T & L & T & R & S & V & G & F & F & S & T & L & T & Y\end{array}$ G C E A I G E A F F V A D L S E Y R O H L R II R A L P R I V TCCCTTCTACGCCGTCAAG GCAACCCGGACCCTTACGTGCTGCAGCTGCTCGGCGCGCT CGGAACCGGATTCGACTGTGCCTCOAACGGTGAGATCGAA GCTGTGCT CAAGCT GGGCATTAACCCTGCCAGGATCATCTACGCTAACCCATCGAAAGCCGCCAGCTTCGT CGTCACGCGGCTGGCCACAATGTCGGGC GACCACGTT GACAACAT GGACGAGCT CGAAAAGATGAAGCGATACCACCCGTCTGGCAAGCTCGTGGGCGATCTIGACGGACGACT CCAAGAGCGC

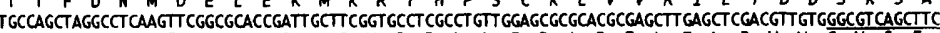

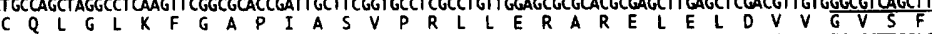
AACTIGGCTCGGGTTGTACGACCCTGATTCATTCCGCGATGCCGTCTACCGCGCG GCGCGITGAGATGGGCAAGCAGGCAGGTTCAGCTTCGACC TCCTCGATGTGG GGTGGTTTGGCCATGACAATTTCGAGATGGTAGCAGGGGGTTGGCCCTGCCATCGATGCCTACTTCCCGGACGAGGACTTGC CCCGGT GGCAAGGAAGT GT CGGCAAAGT CAACGGCCTACGATCATTGCAGAGCCTGGCCGGTITACGT CACTCTGCCTITGCGCT GGCTACCAAC ATCATTGCGGT CGTCG GGCGAGCCTAGCGCGGCGATGGACCATGTCGAAGCAACGCCTAAAGCGCAGGT GATTATTACCAAAATGATGGACTGTACG

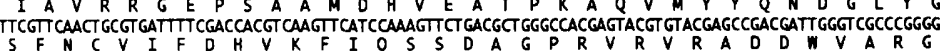
TGCGGCGGGAGGCGGCCGACTCGCGTGGCAGCAGGAGGCCATGACTCTCGAGCGGGCAGCGTATGGGGCCTACGGCGACTCGATCGATTGCGTA A S G E C G R L A L Q Q E A M T L E S C S V W G P T C D S I O C V $D H V E L$ P K G L Q V G D W L V Y E N M G A Y T I C A A S T F N I R R S E I R Y T L G H G Q D A D I V R Q $L$ M L Q * GCATT GCAACCAACAACTTCGTTACATCTAATCCCCTCAGTTTGCCGCTTCCCAAATAATCTCATGCCATTCTCCCTTCCATT GTTTACGTTGGC CATCACAG ACCGAAGATCTGTCCTGCAG
Fig. 1. DNA and deduced amino acid sequence of Umodc. The ORF comprising $1380 \mathrm{nt}$ and the predicted amino acid sequence of 460 residues are shown. The putative TATA box at $-1107 \mathrm{nt}$, two CAAT boxes at $-479 \mathrm{nt}$ and $-461 \mathrm{nt}$, and polyadenylation signal are underlined. The oligonucleotides used to generate the PCR probe are indicated by arrows. amines are required for both differentiative processes, and prompted us to analyse the phenomenon with an odc null mutant.

\section{Cloning of the Umodc gene}

The ODC gene fragment obtained by PCR utilizing $U$. maydis DNA (Torres-Guzman et al., 1996) was used as a probe to screen a genomic library of $U$. maydis (Schulz et al., 1990). Eight positive clones were obtained out of 12000 recombinant phages. SalI fragments of about 4-5 kbp were recovered and cloned into pBKS + . After restriction analysis and hybridization with the PCR fragment, plasmid F2 was selected for further studies. Nucleotide and amino acid sequences of a Xhol-Pst I fragment comprising $3.18 \mathrm{kbp}$ are shown in Fig. 1. A continuous ORF encoding a polypeptide of 460 amino acids with a molecular mass of $50600 \mathrm{Da}$ was observed. No consensus splicing sequences were detected. A putative TATA box was identified at $-1107 \mathrm{bp}$, and two possible CAAT boxes were located at -479 and -461 bp. A consensus polyadenylation signal was also identified. The amino acid sequence of $U$. maydis ODC showed high similarities with other ODCs. The ones with the highest degree of similarity were those from Saccharomyces cerevisiae (Fonzi \& Sypherd, 1987) and 


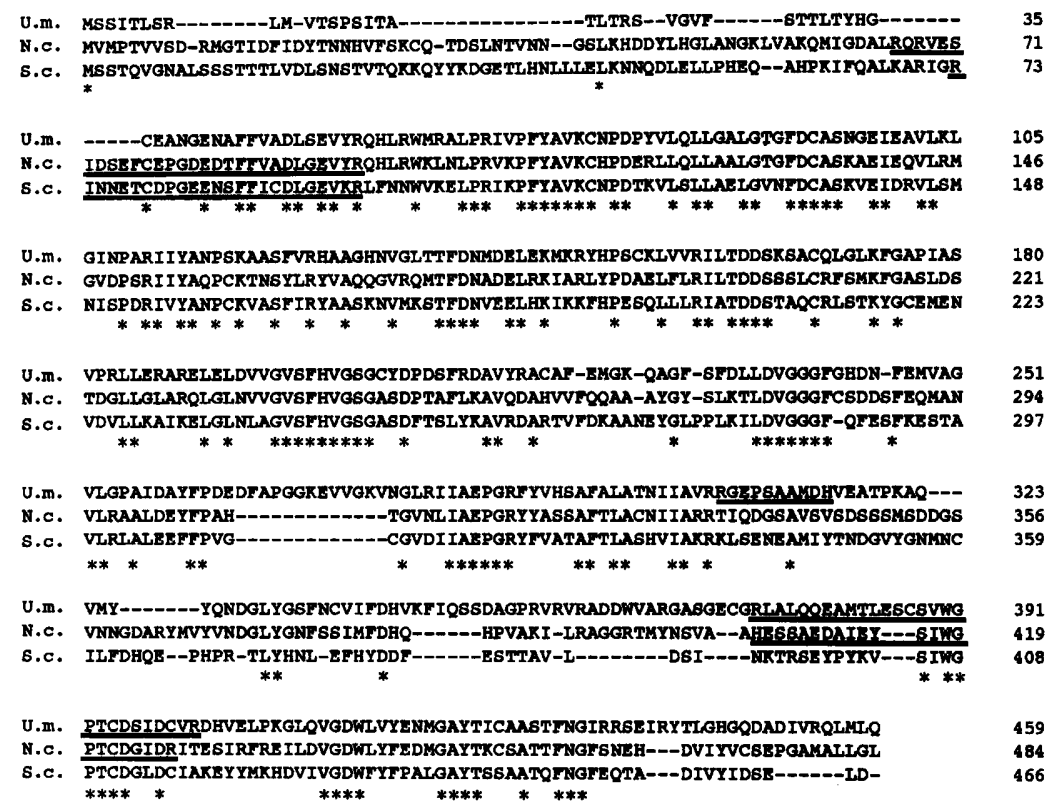

Fig. 2. Multiple amino acid alignment as derived by maximal homology of ODCs from $U$. maydis (U.m.), N. crassa (N.C.) and S. cerevisiae (S.c.). Asterisks indicate positions of complete identity among all sequences. The putative PEST regions are underlined.
Neurospora crassa (Williams et al., 1992) (Fig. 2). The ODCs from $U$. maydis and N. crassa share $40.3 \%$ identical amino acids. This value is higher than the homology existing among $U$. maydis and $S$. cerevisiae $(31.8 \%)$, but lower than the homology between $S$. cerevisiae and N. crassa (46\%). Higher homology was observed in the central part, compared to the aminoand carboxy-termini of the proteins.

Two putative PEST regions, characteristic of proteins with a high rate of turnover (Rogers et al., 1986), but with low PEST scores of -11.8 and -9.21 , were identified, respectively, in residues $306-315$ and 374-401 of the protein, using the algorithm described by Rechsteiner \& Rogers (1996). The second one is located at a similar position to the second PEST region identified in the ODC from N. crassa (residues 405-427) (Williams et al., 1992). This PEST region is absent in $S$. cerevisiae.

U. maydis DNA digested with BamHI, EcoRI, HindIII, PstI or Xhol was probed with a radiolabelled $900 \mathrm{bp}$ Pst I-XhoI fragment of the gene. A single fragment was observed in all cases (Fig. 3). This result suggests that the fungus contains a single ODC gene, Umodc. Northern analysis of $U$. maydis RNA revealed a single transcript of $U \bmod c$ with a size of approximately $2.5 \mathrm{~kb}$. Transcript analysis during the yeast-to-mycelium transition revealed that no significant changes in mRNA levels occurred at this step (Fig. 4).

\section{Null odc mutants of $U$. maydis obtained by gene substitution}

We utilized a method of double homologous recombination (Fotherinham \& Holloman, 1989). The BglII fragment containing the coding region of the gene was subcloned into plasmid p T7-7 in which the Smal site had been previously deleted. A central StuI-SmaI fragment of $584 \mathrm{bp}$ in length was removed. A SalI fragment containing the hygromycin resistance cassette (Tsukuda et al., 1988) was then ligated to the only XhoI site of the ODC sequence (see Fig. 5a). The plasmid was digested with $B g l \mathrm{II}$, and the linear DNA fragment obtained was utilized to transform the FB2 wild-type strain of $U$. maydis. Transformants were selected and purified in minimal solid medium containing hygromycin $(200 \mu \mathrm{g}$ $\mathrm{ml}^{-1}$ ) and $1 \mathrm{mM}$ putrescine. From eight original hygromycin-resistant transformants, three were selected for further analysis. Transformants were analysed by Southern hybridization, utilizing the whole BglII fragment or a BamHI-ClaI fragment of the hygromycin resistance gene $(1046 \mathrm{bp})$ as probes. In two of the mutants, the original $2.08 \mathrm{kbp}$ fragment of the wild-type was substituted by a $4.0 \mathrm{kbp}$ fragment containing the hygromycin resistance cassette, whereas in the third one an ectopic incorporation of the substitution cassette occurred (Fig. 5b). This last result agrees with the observation that recombination in $U$. maydis is not $100 \%$ homologous (Fotherinham \& Holloman, 1989, 1990). One of the null mutants (LG4) was used for further experiments.

\section{Determination of the phenotype of the odc null mutant}

The null mutant behaved as a polyamine auxotroph. When cells grown in a complex medium containing $1 \mathrm{mM}$ putrescine were inoculated into polyamine-free synthetic medium, the mutant grew at a rate not different from the wild-type for about $12-16 \mathrm{~h}$, before a reduction in growth rate occurred. When these cells were recovered, washed with water and reinoculated into fresh synthetic medium, no growth took place unless putrescine was added (Table 2). ODC activity from the wild-type and mutant strains was measured in cells grown for $6 \mathrm{~h}$ in polyamine-free minimal medium. ODC specific activity [as pmol $\mathrm{CO}_{2}$ liberated $\mathrm{min}^{-1}$ (mg cell 

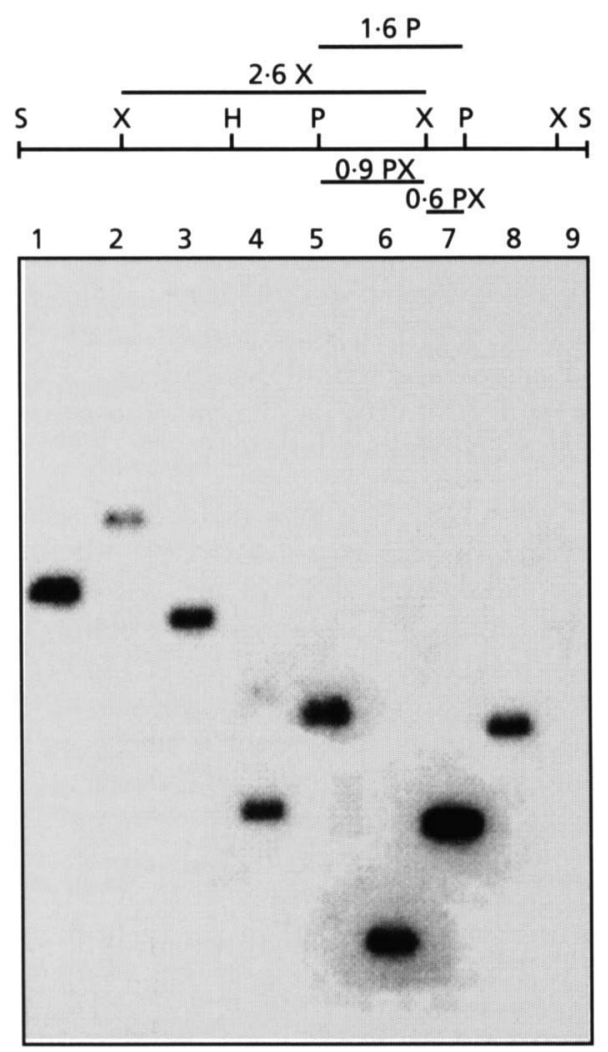

Fig. 3. Southern blot analysis of $U$. maydis genomic DNA. DNA digested with BamHI (lane 1), EcoRI (lane 2), HindIII (lane 3), Pstl (lane 4) or Xhol (lane 5) was probed with a Pstl-Xhol radiolabelled fragment of $900 \mathrm{bp}$ from Umodc. As controls, Umodc gene fragments were run in lanes 6-9. Lanes: 6, Pstl-Xhol fragment of $900 \mathrm{bp} ; 7$, Pstl-Pstl fragment of $1.6 \mathrm{kbp}$; 8, Xhol-Xhol fragment of $2.6 \mathrm{kbp} ; 9$, Pstl-Xhol fragment of 600 bp. H, HindIII; P, Pstl; S, Sall; X, Xhol.

(a)

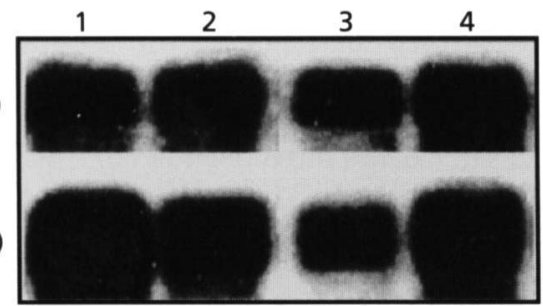

Fig. 4. Northern blot analysis of the Umodc transcript. Total RNA from yeast cells incubated for $4.5 \mathrm{~h}$ was isolated and blotted (lanes 1 and 2). Cells were transferred to fresh medium of pH 7.0 or 3.0 to obtain yeast or mycelial growth, respectively. After $3 \mathrm{~h}$ incubation, total RNA from yeast (lane 3 ) or mycelial cells (lane 4) was isolated and blotted. (a) RNA was hybridized with the Pstl-Xhol radiolabelled fragment of $900 \mathrm{bp}$ from Umodc; (b) as a control, the membrane was hybridized with the carboxin resistance gene of $U$. maydis.

protein $)^{-1}$ ] in the wild-type was approximately 30 . However, the specific activity of the mutant was approximately $0 \cdot 5$, a value probably representing background. (a)
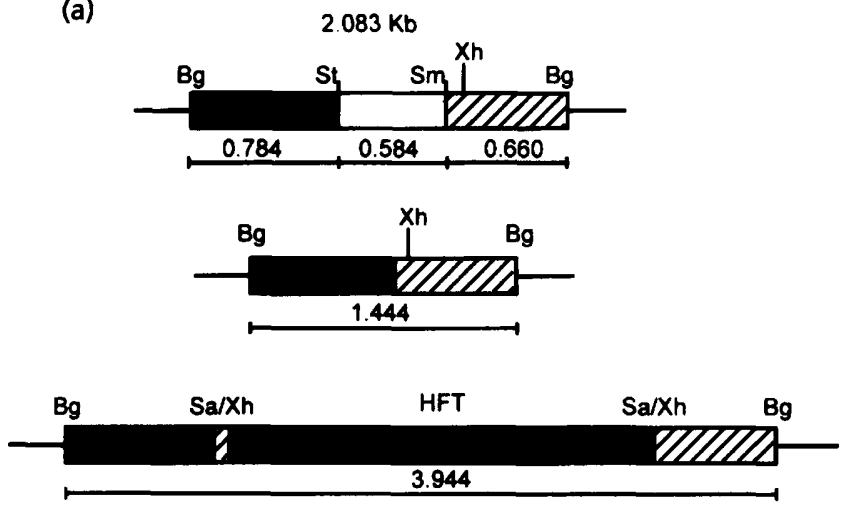

(b)

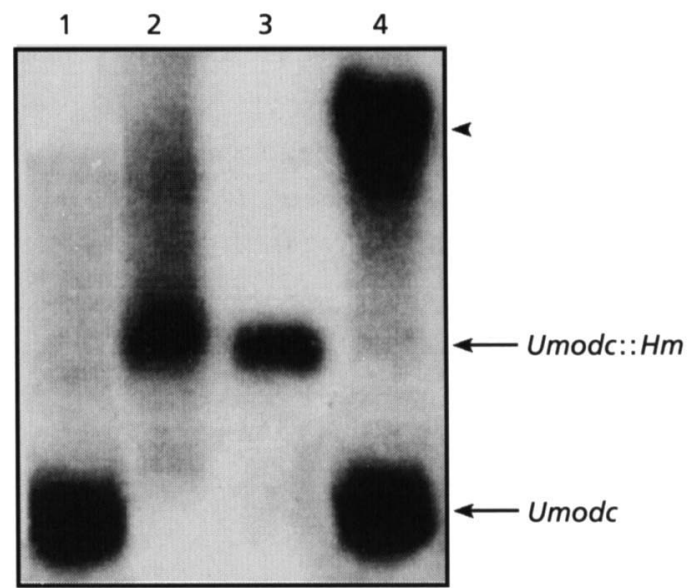

Fig. 5. Strategy for Umodc replacement. (a) Scheme of the strategy followed. An internal Stul-Smal fragment ( $584 \mathrm{bp}$ ) was deleted. After ligation, the hygromycin resistance cassette was inserted into the single $X$ hol site. The thin line is the pT7-7 vector. Bg, Bg/ll; Sa, Sall; Sm, Smal; St, Stul; Xh, Xhol; HFT, hygromycin resistance cassette. (b) Southern blot analysis of wild-type and transformants probed with the whole Bg/ll fragment of the construction. Lanes: 1, wild-type; $2, L G 3 ; 3$, LG4; 4, LG7. The arrowhead indicates the ectopic integration.

Table 2. Requirement of putrescine for growth of the U. maydis null mutant

Cells were grown in minimal medium ( $\mathrm{pH} 7 \cdot 0$ ). After $20 \mathrm{~h}$, growth was measured, cells were washed and reinoculated into fresh minimal medium. After $20 \mathrm{~h}$, more growth was measured again.

\begin{tabular}{|c|c|c|c|}
\hline \multirow{2}{*}{$\begin{array}{l}\text { Incubation } \\
\text { cycle }\end{array}$} & \multirow{2}{*}{$\begin{array}{c}\text { Putrescine } \\
(5 \mathrm{mM})\end{array}$} & \multicolumn{2}{|c|}{ Growth ( $\mu \mathrm{g}$ protein $\left.\mathrm{ml}^{-1}\right)^{*}$} \\
\hline & & $\begin{array}{c}\text { FB2 (parental } \\
\text { wild-type) }\end{array}$ & LG4 (odcs) \\
\hline \multirow[t]{2}{*}{1 st } & No & 510 & 432 \\
\hline & Yes & 600 & 582 \\
\hline \multirow[t]{2}{*}{ 2nd } & No & 395 & 19 \\
\hline & Yes & 486 & 282 \\
\hline
\end{tabular}

*Inoculum: 1st cycle, 17-22 $\mu \mathrm{g}$ protein $\mathrm{ml}^{-1} ;$ 2nd cycle, 14-16 $\mu \mathrm{g}$ protein $\mathrm{ml}^{-1}$. 
In contrast to its growth requirements, higher levels of putrescine than those accumulated in polyamine-containing medium were required by the mutant to grow in mycelial form. Cells incubated in synthetic medium of $\mathrm{pH} 3.0$ (conditions at which the wild-type grows in the form of mycelium; Ruiz-Herrera et al., 1995a) containing less than $0.5 \mathrm{mM}$ putrescine grew with yeast-like morphology, even after $48 \mathrm{~h}$ incubation. However, cells incubated in medium containing $1 \mathrm{mM}$ or more putrescine or $5 \mathrm{mM}$ spermidine gave rise to a homogeneous mycelial population. In solid medium of $\mathrm{pH} 3$, the null mutant failed to form mycelial ('fuzz') colonies as the wild-type does (Ruiz-Herrera et al., 1995a); instead, smooth colonies were formed. Representative photographs illustrating this behaviour are shown in Fig. 6.

\section{DISCUSSION}

Inhibition of teliospore germination and yeastmycelium transition in $U$. maydis by the ODC competitive inhibitor $\mathrm{DAB}$ agrees with results that we have obtained with other fungal systems (for a review see Ruiz-Herrera, 1994). According to these data, both differentiation processes require levels of diffusible polyamines higher than those necessary to sustain the growth of the organism. An interesting point is why differentiation is more sensitive than vegetative growth to the DAB effect. A plausible explanation lies in the observation that fungi may contain more than one pool of ODC, one of which is resistant to the drug in vivo but not in vitro (Martinez-Pacheco \& Ruiz-Herrera, 1993; Guevara-Olvera et al., 1993).

Cloning of the Umodc gene and construction of an odc null mutant of the fungus by reverse genetics allowed a more thorough examination of the role of polyamines in the dimorphic transition of the fungus. The deduced amino acid sequence of the $U \bmod c$ gene product showed high homology with ODCs from other organisms. Highest homology was observed with the ODCs from $S$. cerevisiae and $N$. crassa, although this was lower than the homology existing between the enzymes from these two organisms. This would be expected since the latter are ascomycetes and $U$. maydis is a basidiomycete. Previously we have reported that ODC PCR fragments of fungi form a compact group when compared with the corresponding regions of ODCs from other sources, and that their homology agrees with their phylogenetic relationships (Torres-Guzman et al., 1996). Most of the systems analysed (Fonzi \& Sypherd, 1985, 1987; Heby \& Persson, 1990; Williams et al., 1992) contain only one ODC gene. Our results confirmed that in agreement with these data, $U$. maydis also contains a single gene encoding ODC. The observation that the Umodcs mutant is a putrescine auxotroph indicates that in $U$. maydis, as in other fungi and animals, the only functional pathway for polyamine biosynthesis involves ODC. Other organisms such as bacteria and plants possess an additional biosynthetic pathway which involves arginine decarboxylase (Tabor \& Tabor, 1985; Slocum et al., 1984).
Two putative PEST regions with a low score were identified in $U$. maydis ODC. These are sequences characteristic of proteins with a high rate of turnover (Rogers et al., 1986; Rechsteiner \& Rogers, 1996). In $S$. cerevisiae ODC, a single PEST region exists (Fonzi \& Sypherd, 1987), whereas the $N$. crassa enzyme contains two of them (Williams et al., 1992). Whether regions with the low values obtained are significant or not remains doubtful. If they were, regulation of the levels of ODC, at least in part, would occur through the control of its rate of degradation, as happens in other systems (Hayashi et al., 1996).

U. maydis ODC transcript appears to display a long leader region. The only transcript identified was approximately $2.5 \mathrm{kbp}$, contrasting with the $1.38 \mathrm{kbp}$ long coding region. This agrees with results generally obtained with ODCs (Heby \& Persson, 1990; Williams et al., 1992). These observations suggest that the putative TATA box located far upstream is functional (the one from human ODC, for example, is located at $-763 \mathrm{bp}$; van Steeg et al., 1989), but this remains undecided. Genes without TATA boxes have been described (e.g. Hudspeth \& Grula, 1989; Moffat et al., 1994). The same applies for the putative CAAT boxes identified in wrong order to the TATA box. The presence of a large leader region suggests a complex regulation of the transcript (Kameji et al., 1993). Experiments from the group of Rowland Davis have revealed that the long leader of the N. crassa SPE1 transcript is involved in the regulation of ODC levels by polyamines (Williams $e$ t al., 1992; Pitkin et al., 1994); whereas an upstream region (UAR) is responsible for transcription activation (Pitkin et al., 1994). Interestingly, their data suggested that regulation of ODC activity was not essential for the growth of the fungus.

Once the Umodc gene was cloned, we proceeded to its substitution. To our knowledge, the odc U. maydis null mutants described here, and null mutants of the $S$. cerevisiae SPE1 gene (Fonzi \& Sypherd, 1987; Balasundaram et al., 1994), are the only ones where ODC gene knockouts have been accomplished in fungi. As indicated above, the odc null mutant of $U$. maydis behaved as a putrescine auxotroph, but it was able to accumulate a polyamine pool large enough to permit cell growth for about $12-16 \mathrm{~h}$. This behaviour agrees with

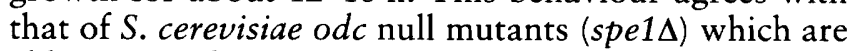
able to grow for approximately $20 \mathrm{~h}$ in a polyamine-free medium (Balasundaram et al., 1994). The observation that polyamines restore normal growth of the null mutant indicates that the only role of ODC in U. maydis is the synthesis of putrescine. This result agrees with data obtained with spe1s mutants of $S$. cerevisiae (Balasundaram et al., 1994) and nonsense odc mutants of N. crassa (Davis et al., 1987).

Since the null mutant of $U$. maydis was able to grow temporarily in the absence of exogenously added putrescine, we were able to determine its capacity to perform the dimorphic transition under those conditions. The observation that even in the presence of 

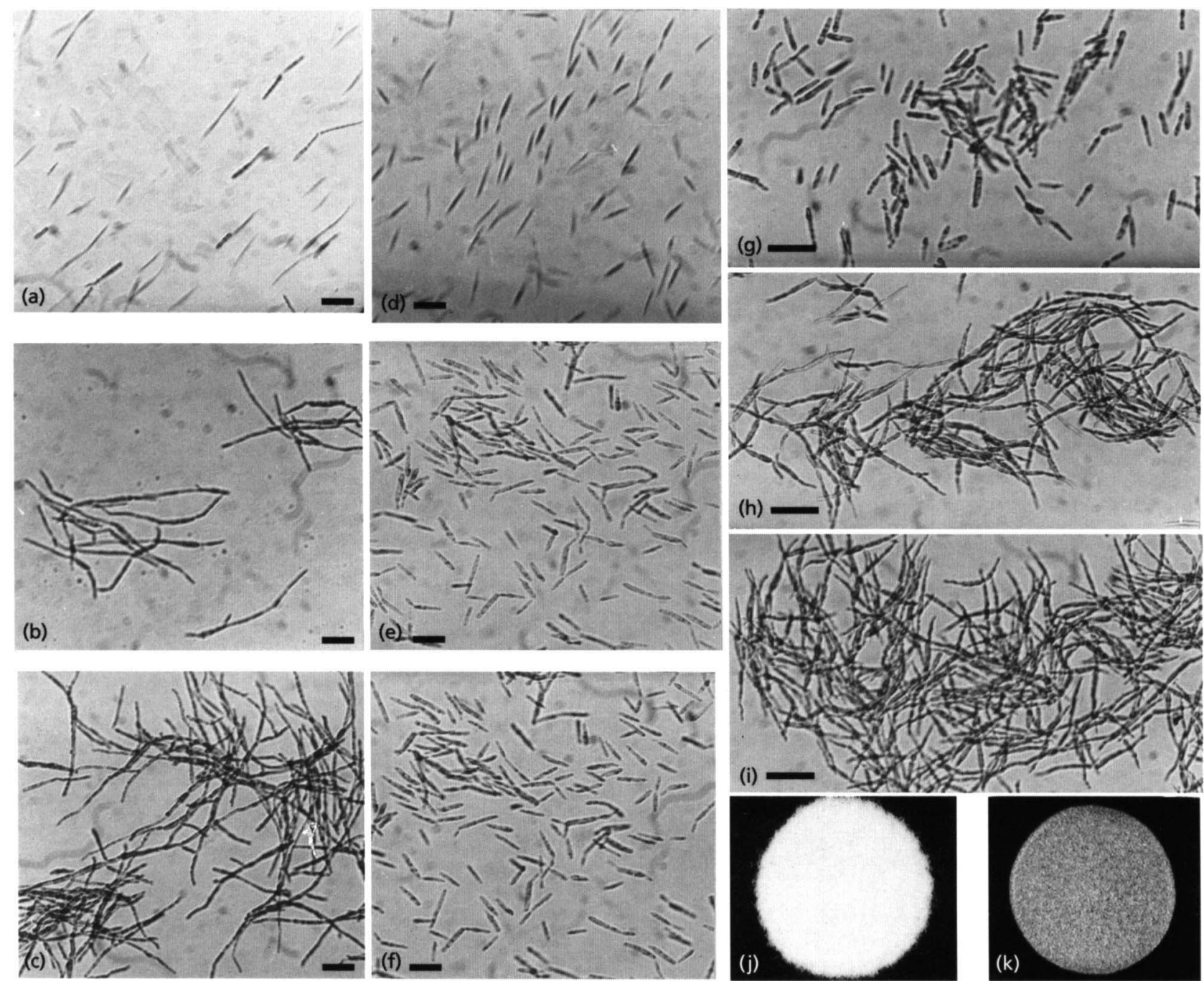

Fig. 6. Cell and colonial morphology of wild-type and null odc mutant of $U$. maydis. Wild-type grown in liquid synthetic medium without polyamines of pH 3.0: (a) zero time; (b) $6 \mathrm{~h}$; (c) $12 \mathrm{~h}$. LG4 mutant grown as above: (d) zero time; (e) $6 \mathrm{~h}$; (f) $12 \mathrm{~h}$. Mutant grown with $0.4 \mathrm{mM}(\mathrm{g}), 1 \mathrm{mM}(\mathrm{h})$ or $5 \mathrm{mM}$ (i) putrescine. Colonial growth on charcoal-containing minimal medium of $\mathrm{pH} 3.0$ : (j) wild-type; (k) mutant. Bar, $10 \mu \mathrm{m}$.

putrescine concentrations lower than $0.5 \mathrm{mM}$, the fungus multiplied at an almost normal rate but was unable to carry out the yeast-to-mycelium transition is strong evidence for the role of polyamines in this process. Support for this conclusion is offered by the observation that larger amounts of putrescine or spermidine were necessary to restore the normal dimorphic phenotype of the fungus. These results eliminate the possibility that the phenotype was due to the accumulation of ornithine or products derived from it, or $S$-adenosylmethionine. It is generally accepted that the only role of putrescine in cell growth is to serve as a spermidine precursor (we have observed that $U$. maydis contains no spermine). Indeed, $S$. cerevisiae null mutants in the SPE2 gene encoding $S$-adenosylmethionine decarboxylase are spermidine or spermine auxotrophs (Balasundaram et al., 1991). Nevertheless, whether putrescine plays a specific role or not in differentiation remains an open question, since it can be derived from spermidine by the action of polyamine oxidase (McCann et al., 1987).

An important question to be answered in the future is the mode of action of polyamines in cell differentiation. It is known that due to their polycationic nature, polyamines bind to cellular anions. In E. coli, $90 \%$ of the total spermidine is bound to RNA, $5 \%$ to DNA and $0.8 \%$ to membrane lipids (Miyamoto et al., 1993). Accordingly, a nonspecific role of polyamines has been suggested (Davis et al., 1992). Nevertheless, we have described at least one specific role for them-the inhibition of cytosine-DNA methylases (Ruiz-Herrera et al., 1995b). Accordingly, a tentative hypothesis may be that they contribute to the regulation of the transcription of genes involved in differentiative processes. 


\section{ACKNOWLEDGEMENTS}

This work was partially supported by CONACYT, México, and by ICGEB (CRP/MEX95-01 h2). L. G.-O. is a predoctoral fellow from CONACYT. J.R.-H. is National Investigator, México.

\section{REFERENCES}

Balasundaram, D., Tabor, C. W. \& Tabor, H. (1991). Spermidine or spermine is essential for the aerobic growth of Saccharomyces cerevisiae. Proc Natl Acad Sci USA 88, 5872-5876.

Balasundaram, D., Xie, Q. W., Tabor, C. W. \& Tabor, H. (1994). The presence of an active $S$-adenosyl methionine decarboxylase gene increases the growth defect observed in Saccharomyces cerevisiae mutants unable to synthesize putrescine, spermidine, and spermine. J Bacteriol 176, 6407-6409.

Banuett, F. (1992). Ustilago maydis, the delightful blight. Trends Genet 8, 174-180.

Calvo-Mendez, C., Martinez-Pacheco, M. \& Ruiz-Herrera, J. (1987). Regulation of ornithine decarboxylase in Mucor bacilliformis and Mucor rouxii. Exp Mycol 11, 270-277.

Davis, R. H., Hynes, L. V. \& Eversole-Cire, P. (1987). Nonsense mutation of the ornithine decarboxylase structural gene of Neurospora crassa. Mol Cell Biol 7, 1122-1128.

Davis, R. H., Morris, D. R. \& Coffino, P. (1992). Sequestered end products and enzyme regulation: the case of ornithine decarboxylase. Microbiol Rev 56, 280-290.

Fonzi, W. A. \& Sypherd, P. (1985). Expression of the gene for ornithine decarboxylase of Saccharomyces cerevisiae in Escherichia coli. Mol Cell Biol 5, 161-166.

Fonzi, W. A. \& Sypherd, P. (1987). The gene and primary structure of ornithine decarboxylase from Saccharomyces cerevisiae. J Biol Chem 262, 10127-10133.

Fotherinham, S. \& Holloman, W. K. (1989). Cloning and disruption of Ustilago maydis genes. Mol Cell Biol 9, 4052-4055.

Fotherinham, S. \& Holloman, W. K. (1990). Pathways of transformation in Ustilago maydis determined by DNA conformation. Genetics 124, 833-843.

Guevara-Olvera, L., Calvo-Mendez, C. \& Ruiz-Herrera, J. (1993). The role of polyamine metabolism in dimorphism of Yarrowia lipolytica. J Gen Microbiol 139, 485-493.

Hayashi, S. I., Murakami, Y. \& Matsufuji, S. (1996). Ornithine decarboxylase antizyme: a novel type of regulatory protein. Trends Biochem Sci 21, 27-29.

Heby, O. \& Persson, L. (1990). Molecular genetics of polyamine synthesis in eukaryotic cells. Trends Biochem Sci 15, 153-158.

Holliday, R. (1974). Ustilago maydis. In Handbook of Genetics, vol. 1, pp. 575-595. Edited by R. C. King. New York: Plenum Press.

Hudspeth, R. L. \& Grula, J. W. (1989). Structure and expression of the maize gene encoding the phosphoenolpyruvate carboxylase isozyme involved in $\mathrm{C} 4$ photosynthesis. Plant Mol Biol 12, 579-589.

Kameji, T., Hayashi, S. I., Hoshino, K., Kakinuma, Y. \& Igarashi, K. (1993). Multiple regulation of ornithine decarboxylase in enzymeoverproducing cells. Biochem J 289, 581-586.

Keon, J. P. R., White, G. A. \& Hargreaves, J. A. (1991). Isolation, characterization and sequence of a gene conferring resistance to the systemic fungicide carboxin from the maize smut pathogen, Ustilago maydis. Curr Genet 19, 475-481.

McCann, P. P., Pegg, A. E. \& Sjoerdsma, A. (1987). Inbibition of
Polyamine Metabolism: Biological Significance and Basis for New Therapies. Orlando: Academic Press.

Martinez-Pacheco, M. \& Ruiz-Herrera, J. (1993). Differential compartmentation of ornithine decarboxylase in cells of Mucor rouxii. J Gen Microbiol 139, 1387-1394.

Martinez-Pacheco, M., Rodriguez, G., Reyna, G., Calvo-Mendez, C. \& Ruiz-Herrera, J. (1989). Inhibition of the yeast-mycelial transition and the phorogenesis of Mucorales by diamino butanone. Arch Microbiol 151, 10-14.

Miyamoto, S., Kashiwagi, K., Watanabe, S. \& Igarashi, K. (1993). Estimation of polyamine distribution and polyamine stimulation of protein synthesis in Escherichia coli. Arch Biochem Biophys 300, 63-68.

Moffat, B. A., McWhinnie, E. A., Agarwal, S. K. \& Schaff, D. A. (1994). The adenine phosphoribosyltransferase-encoding gene of Arabidopsis thaliana. Gene 143, 211-216.

Pegg, A. E. \& McCann, P. P. (1982). Polyamine metabolism and function. Am J Physiol 243, 212-221.

Pitkin, J., Perriere, M., Kanehl, A., Ristow, J. L. \& Davis, R. H. (1994). Polyamine metabolism and growth of Neurospora crassa strains lacking cis-acting control sites in the ornithine decarboxylase gene. Arch Biochem Biophys 315, 153-168.

Rechsteiner, M. \& Rogers, S.W. (1996). PEST sequences and regulation by proteolysis. Trends Biochem Sci 21, 267-271.

Reyna-Lopez, G. \& Ruiz-Herrera, J. (1993). Polyamines and the phorogenesis of Mucorales. Exp Mycol 17, 79-89.

Rogers, S. R., Wells, R. \& Rechsteiner, M. (1986). Amino acid sequences common to rapidly degraded proteins: the PEST hypothesis. Science 234, 364-368.

Ruiz-Herrera, J. (1994). Polyamines, DNA methylation, and fungal differentiation. Crit Rev Microbiol 20, 143-150.

Ruiz-Herrera, J. \& Calvo-Mendez, C. (1987). Effect of ornithine decarboxylase inhibitors on the germination of sporangiospores of Mucorales. Exp Mycol 11, 287-296.

Ruiz-Herrera, J., Leon, C., Guevara-Olvera, L. \& Carabez-Trejo, A. (1995a). Yeast-mycelial dimorphism of haploid and diploid strains of Ustilago maydis. Microbiology 141, 695-703.

Ruiz-Herrera, J., Ruiz-Medrano, R. \& Dominguez, A. (1995b). Selective inhibition of cytosine-DNA methylases by polyamines. FEBS Lett 357, 192-196.

Sambrook, J., Fritsch, E. F. \& Maniatis, T. (1989). Molecular Cloning: a Laboratory Manual, 2nd edn. Cold Spring Harbor, NY: Cold Spring Harbor Laboratory.

Sanger, F., Nicklen, S. \& Coulson, A. R. (1977). DNA sequencing with chain-terminating inhibitors. Proc Natl Acad Sci USA 74, 5463-5467.

Schulz, B., Banuett, F., Dahl, M., Schlesinger, R., Schăufer, W., Martin, T., Herskowitz, I. \& Kahmann, R. (1990). The b alleles of Ustilago maydis whose combinations program pathogenic development, code for polypeptides containing a homeodomainrelated motif. Cell 60, 295-306.

Slocum, R. D., Kaur-Sawhney, R. \& Galston, A. W. (1984). The physiology and biochemistry of polyamines in plants. Arch Biochem Biophys 235, 1519-1526.

van Steeg, H., van Oostrom, C. T. M., Martens, J. W. M., van Kreyl, C. F., Schepens, J. \& Wieringa, B. (1989). Nucleotide sequence of the human ornithine decarboxylase gene. Nucleic Acids Res 17, 8855-8856.

Tabor, C. W. \& Tabor, H. (1984). Polyamines. Annu Rev Biochem 53, 749-790. 
Tabor, C. W. \& Tabor, H. (1985). Polyamines in microorganisms. Microbiol Rev 49, 81-99.

Torres-Guzman, J. C., Xoconostle-Cazares, B., Guevara-Olvera, L., Ortiz, L., San-Blas, G., Dominguez, A. \& Ruiz-Herrera, J. (1996).

Comparison of fungal ornithine decarboxylases. Curr Microbiol 33, 390-392.

Tsukuda, T., Carleton, S., Fotherinham, S. \& Holloman, W. K. (1988). Cloning and disruption of Ustilago maydis genes. Mol Cell Biol 8, 3703-3707.

Wang, J., Holden, D. W. \& Leong, S. A. (1988). Gene transfer system for the phytopathogenic fungus Ustilago maydis. Proc Natl Acad Sci USA 85, 865-869.

Williams, L. J., Barnett, G. R., Ristow, J. L., Pitkin, J., Perriere, M. \& Davis, R. H. (1992). The ornithine decarboxylase gene of Neurospora crassa: isolation, sequence and polyamine-mediated regulation of its mRNA. Mol Cell Biol 12, 347-359.

Received 10 December 1996; revised 14 February 1997; accepted 19 February 1997. 